\title{
Innovation by Increasing Ideality - A New Method for Overcoming Process Related Problems
}

DOI: 10.12776/QIP.V25I2.1578

\author{
Vladimir Sojka, Petr Lepsik
}

Received: 2021-05-26 Accepted: 2021-06-19 Published: 2021-07-31

\begin{abstract}
Purpose: In production, problems that are difficult to solve could occur. When a classic problem-solving toolset is not enough, a company must accept not fully satisfying solutions or secondary problems. This paper proposes a new method called Innovation by Increasing Ideality (3I), which helps to resolve difficult problems in production.
\end{abstract}

Methodology/Approach: Based on a previous literature review a new method was designed. The method leads the solver by a set of steps that lead to a welldescribed problem, with many ideas or ways, where the solver should search for a satisfying solution. The method is based on TRIZ principles, but it is userfriendly even for users who are not TRIZ specialists but have only basic knowledge of TRIZ principles and its tools. The method is demonstrated in a case study, where a problem with the transportation of parts is successfully solved.

Findings: Newly proposed method, compared with the traditional way of resolving a problem, got a much better solution in a shorter time.

Research Limitation/Implication: Only one example of use. There is a need for more applications in future.

Originality/Value of paper: The paper describes a new method for overcoming difficult problems in production. The method uses TRIZ principles to innovate the process where the problem is. The presented method can serve as a new powerful tool for industrial engineers in practice.

Category: Conceptual paper

Keywords: 3I; problem-solving; process innovation; innovation method; TRIZ 


\section{INTRODUCTION}

Problems related to production or production logistic occurring every day. There are many tools and methods how to deal with most kinds of problems. Generally, a lean thinking toolset can resolve a majority of problems in production.

Sometimes a more difficult problem appears, and no satisfying solution for this problem can be found using the classic toolset of industrial engineering. Partial solutions could lead to secondary problems, new costs, or the problem can occur again. There could be cases when the problem is somehow specific, and it can be solved by using specialised tools or methods. Examples can be seen in many studies. An analytical approach (Meister et al., 2019) is used for resolving problems in complex systems with a significant amount of data. The problem with detecting a special kind of defects could be resolved by using an optimised fuzzy C-mean clustering method. That is shown in the identification of defects on leather surfaces (Mohammed, Kumar and Prasad, 2020). Many authors are proposing a special software as a problem-solving tool. Enhancement of the problem-solving process in a production plant using a knowledge-based multiagent software solution is shown in (Camarillo, Rios and Althoff, 2018). A digital twin as a method for resolving a problem with leather cutting process optimisation is described by Horvathova, Lacko and Hajduová (2019). Machine scheduling problems can be resolved by a multi-objective scheduling approach (Shahzad, Gulzar and Shahzad, 2020). Artificial intelligence and neural networks could help to resolve complex problems. That can be seen in using the artificial neural network to identify factors for industrial productivity (Gutiérrez-Ruiz et al., 2020). Another approach is in Horvat et al. (2020), where communication while solving the problem is improved. Burch, Burch and Batchelor (2019) describe a positive effect to creative problem-solving in groups. The search for that specialised tool can be time-consuming, and there is no certainty that a specialised method was already designed for a specific problem. That is why a generally applicable method for resolving difficult problems in production is needed.

To find a satisfying solution to a majority of difficult problems, the process where the problem is should be innovated. The question is how to approach to effective but easy way to innovate the process or its part. Wu, Lin and Yu (2019) enhanced the innovation of services by customer involvement. An innovative problem-solving approach can also be managed by innovation or ideation contests (Campos-Blázquez, Morcillo and Rubio-Andrada, 2020; Menon, Mishra and Ye, 2020). Another way to pursuit innovation could be a patent analysis (Choi, Lee and Sawng, 2019; Lee, Lee and Lin, 2019). One of the most powerful innovation approaches is the use of systematic creativity represented by TRIZ the Theory of Inventive Problem Solving (Altshuller, 2000; Anosike and Lim, 2014; Caligiana et al., 2017; Harlim and Belski, 2015; Jin, San and Li, 2008; Li, Li and Yang, 2011; Lin et al., 2016; Maia, Alves and Leão, 2015; Navas, 2017; Song and Sakao, 2017). The problem is that TRIZ is complex and challenging to learn (Averboukh, 2003; Azlan, Ariz and Yusof, 2014; Birdi, Leach and 
Magadley, 2012; Brad, 2010; Haines-Gadd, 2015; Ilevbare, Probert and Phaal, 2013; Nakagawa, 2011). That is why there is a low probability that the tools of TRIZ will become a part of industrial engineering's toolset. There is a need for a new method for resolving difficult problems in production. Powerful as TRIZ, but easy to use by industrial engineers in practice.

This paper aims to develop a new method based on the TRIZ principles for overcoming problems in production processes. The method is also demonstrated on the real problem with the transportation of heat exchangers in production logistics.

\subsection{Problem-Solving in Production by TRIZ}

The Theory of Inventive Problem Solving, known as TRIZ, is a set of tools and methods for overcoming challenging problems. Many authors already published studies aiming at the use of TRIZ for problem-solving in production processes or processes related to production. Swee et al. (2017) try to improve the quality of production by applying TRIZ tools. Lin et al. (2016) used TRIZ tools to optimise a coffee roasting process. The integration of TRIZ methods into an approach for process and product innovation is described by $\mathrm{Li}$ et al. (2017). Livotov et al. (2018) use TRIZ with process intensification. Alves, Sousa and Navas (2020) describing the possible integration of Lean thinking tools with TRIZ ideas. Morgado, Sandiães and Navas (2019) use a contradiction matrix together with SMED and 5S to improve management activities. Russo and Spreafico (2020) describe a guideline for using TRIZ for problem-solving in the way of ecoinnovation. Sojka and Lepšík (2020a) reviewing the implementation of TRIZ, or TRIZ with other methods for process improvement. Results are that there is a need for a method that is easier to use because TRIZ is hard to use by engineers in companies who are not TRIZ experts. There is a possible way how to approach efforts to use the TRIZ to enhance the production processes, a new standalone method based on TRIZ principles (Sojka and Lepšík, 2020b).

Even that, many authors described the use of TRIZ for problem-solving. TRIZ is still hard and slow to learn. For engineers in companies, TRIZ training is a longterm goal, so they prefer to learn classic tools that are faster and easier to learn and can provide good solutions for most problems in production. To reach more frequent use of TRIZ a more straightforward approach is needed. The first thing could be a clear guide on how to describe problems and solve them using basic principles of TRIZ, even if the solver has only a few experiences with TRIZ.

\section{METHODOLOGY}

\subsection{Development of the New Method}

The new method is mainly based on the ideality principle of TRIZ. The level of the ideality of the technical system is described by equation (1) below (Anosike 
and Lim, 2014; Domb, 2007; 1997; Slocum, Lundberg and Walter, 2003; Soderlin, 2003):

$$
\text { Ideality }=\frac{\sum \text { benefits }}{\sum \text { harms }+\sum \text { costs }} .
$$

Benefits, from the ideality equation (1), represent a sum of positive functions and their effects on the system, harms represent negative functions and their effects on the system, and costs represent costs of the system and costs for innovation. The main idea is that by resolving the problem, the system, in this case, the production process, should be more ideal.

The method for resolving difficult problems in production should use the TRIZ principles in order to be powerful, and at the same time, it should be easy to use and learn. That is why only some TRIZ tools were used, and the application of the method guides the solver. Each step has a clear question or instruction to answer. The method is based on a set of questions, leading to a deeper understanding of the physical principles of the problem, and it allows the solver to look at problems from a different perspective. That allows to use of TRIZ basic tools more easily, and it should provide a satisfying solution to the problem.

\subsection{Innovation by Increasing Ideality (3I)}

The 3I method for overcoming problems is not focusing on the problem itself but innovating activities where the problem occurs. The method's main goal is to innovate the process and increase its degree of ideality in the way of overcoming the problem. However, the problem is not resolved but overcame by increasing the ideality of the process. The steps of the method are: the description of the problem, the purpose of the process step where the problem occurs, the principle of the process, the ideal state of the process, questions how to achieve the ideal state, inspiration in scientific effect and trends, overcoming contradictions, use of other TRIZ tools, list of ideas and searching for final solution based on the list of ideas.

The first thing is to determine what the problem is and where the problem occurs. That should be the easy part. This step aims to describe and know that there is a problem in production that occurs in a specific step or steps. The next step is to describe the purpose of the activity, where the problem occurs. The answer to the question "What is the purpose of this activity?" describes the goal of the process step. That helps the solver to understand what is needed to achieve. After that, a question about the principle of activities is set. The principle on which a current state of activity is based. "What is a principle of the activity, where the problem occurs." The answer should be a simple description of a physical principle used to achieve the purpose of the activity. These questions and their answers give the solver a clear description of what is needed and how it is made now. After determining these initial answers, more TRIZ based questions can continue with 
the description and solution of the problem. The crucial question is, "What is the ideal state of this activity?". By answering this, the solver should try to find an ideal state on how to achieve the purpose of the activity. To describe the ideal state, words as "self" and "itself" are used. The ideal state gives a way in which the solver should try to find a new solution for improving the activity to prevent current problems. After the ideal state is described, there can be seen what is between the current state and the ideal one. In other words, what we should do, or should not do, to achieve an ideal state. It is almost impossible to achieve the ideal state, so there should be an effort to be as close as possible to this ideal state. In order to get closer to the ideal state, an ideality question should be made. This question says what is needed to eliminate to achieve a more ideal system. It is based on the trimming activities from TRIZ. When the ideal state is described and the ideality questions give way to what to do, searching for solutions can begin.

Inspiration is the first step of a search for solutions. The catalogue, or database, of scientific effects is used for searching for existing innovative solutions to a similar problem. Evolution trends of TRIZ can also provide a way for innovation of the process' activity. Finally, research in technologies and other fields can provide other innovative solutions that were discovered before. Previous steps help the solver understand the problem and process' step, so it is easier to use inspiration tools to find a satisfying solution. The ideality question is also a good start to determine contradiction. When the ideality question is set, a technical contradiction can be described. The technical contradiction can be solved by the use of a contradiction matrix or other TRIZ tools. Alternatively, the problem can be intensified, and physical contradiction can be determined and resolved. Resolving technical or physical contradictions should bring a powerful solution to the process innovation. Contradiction matrix, inventive principles, separation principles, or substance field analysis could be used for that. For more solutions, other TRIZ tools can be used. For example: 9 windows, RCA, Little Men Method, etc.

All ideas and possible solutions are collected and should be written into a list of solutions. This list is the output from the 3I method. For the final solution, the inspiration step can be done again. After solutions are found, there is a need to compare them with the real world. Sometimes a very good solution cannot be easily applied to the real process because there is another problem linked to it, and the solver could miss it during the solution process. In that case, a new problem can be solved again using TRIZ tools or a different solution (less ideal one) from the list of solutions that can be chosen. The main steps of the 3I method are shown in Figure 1 below. 


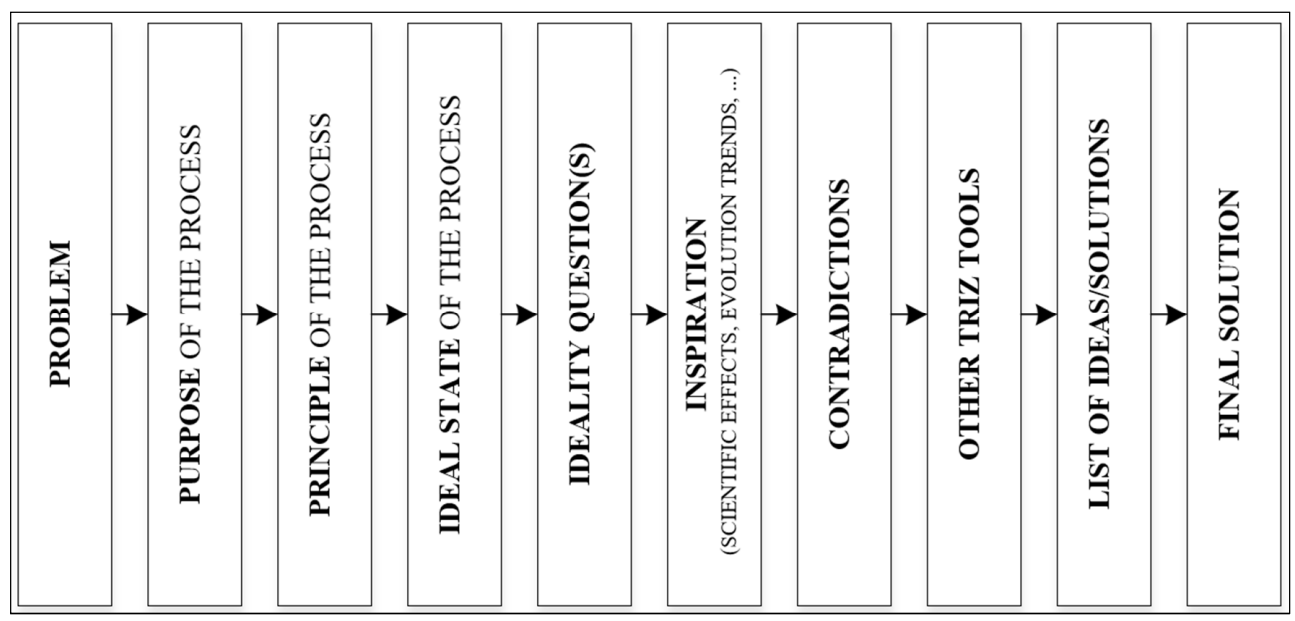

Figure 1 - Main Steps of Innovation by Increasing Ideality Method (3I)

\section{RESULTS}

A case study was made to show how the Innovation by Increasing Ideality method for overcoming problems in production processes works. The application of this method was made in a company in the Czech Republic, which produces custom heat exchanger units. The case study was made on a problem with the transportation of parts from storage to processing line in a different building. The overall process is about the assembly of heat exchanger modules.

\subsection{A Case Study - Problem with Transportation}

The problem occurs while exchangers should be transported from storage to the assembly line. It is a custom production, so there is often a need only for few pieces of exchangers. Nowadays, exchangers are stored on pallets. The whole palette is transported to the assembly line, where workers open the palette and use a crane to take the demanded number of exchangers. After that palette is closed again, and the rest of the exchangers are transported back to the storage.

The problem is that there are fewer exchangers inside of the palette and can be damaged by themselves because the route between storage and production line is not flat; this should be solved. In many cases, it is solved by connecting exchangers together. However, sometimes only one or two exchangers are left, so even if they are connected, they have weak stability and can be damaged during transportation. Palettes with exchangers can be seen in the Figure 2 below. 


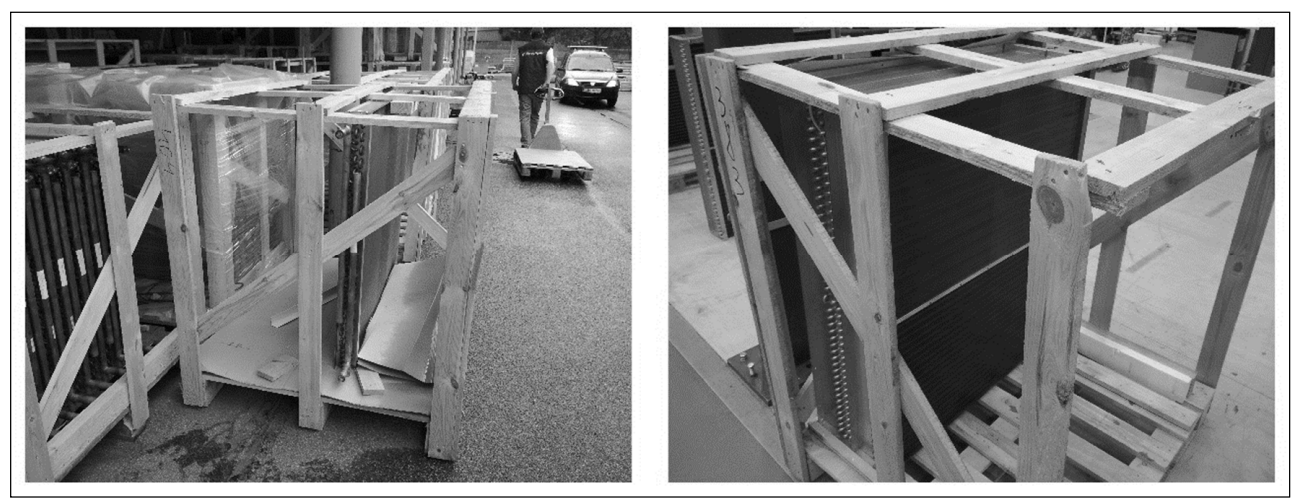

Figure 2 - Palettes with Last Exchangers, in Storage and Near the Processing Line

An even bigger problem is the transport itself from storage to line and back several times. Also, there is quite a lot of time for opening and closing palettes by the line workers. The productivity of the line is decreasing with each opening and closing of the palette. From these reopening-reclosing procedures, there is dirt on the workplace, causing other related additional works and problems. The idea is to transport only the demanded number of exchanges from storage to the assembly line. The problem is to find a suitable solution on how to do it. Exchangers are big and heavy, so they cannot be lifted by hand, and there is no crane in storage. Storage is in a different building than the assembly line, and the route between is not flat and is full of obstacles. And because it is not a crucial problem, the company's management does not want to spend a big amount of cost on the solution. Some examples of previously proposed solutions and their negative effects can be seen in the Table 1 below.

Table 1 - Previous Solutions and Their Harms

\begin{tabular}{|l|l|}
\hline Previous solution & Negative effects \\
\hline $\begin{array}{l}\text { Fixation of parts inside of palette on the way } \\
\text { back (rope, support, stoppers, ...) }\end{array}$ & $\begin{array}{l}\text { There is still transport back, a place for storing, } \\
\text { extra work }\end{array}$ \\
\hline Transport via "A" palettes & $\begin{array}{l}\text { Transport back, if more than two exchangers left - } \\
\text { more palettes are needed }\end{array}$ \\
\hline Open palettes in storage & No crane in storage \\
\hline Use of "T" constructions & Impossible (exchangers without frame) \\
\hline Transport via small wheels & Storing place, hard handling, no crane in the storage \\
\hline Store rest exchangers by line & No room for storage near the line \\
\hline
\end{tabular}

Although many attempts to solve this problem were made, and many proposed solutions were tried. Every time another negative effect related to the solution appeared. 


\subsection{Case Study - Use of the 3I Method to Overcome the Problem}

On the problem situation described above, the 3I method for resolving difficult problems described in chapter 2.2. was used.

Firstly, a problem must be clearly described. The problem is that exchangers (parts) are damaged during transportation. When a problem was studied deeper, it came up that only exchangers which are transported back to storage and then again to the line are damaged because of weak stability inside of palettes. The real problem is that there is a need to transport parts (exchangers) back to storage. The second step of the method is to describe the purpose of the process where the problem occurs. The purpose is clearly to deliver exchangers (parts) to the assembly line. The principle of how the purpose is currently achieved can be described as the transportation of parts on palettes. There are residual parts that must be transported back to storage. There can be seen that problem occurring because of the principle of the activity. After purpose and principle are known, the ideal state can be described. More than one description of the ideal state can be proposed. The ideal state is when the exact number of parts (exchangers) is safely delivered to the assembly line. Or the exact number of parts appears near to the assembly line. The third formulation can be, there is no need to transport parts/or transport them back. Ideality questions can be described as "How can be parts transported in needed number, and without damage?" or "How to have parts near to assembly line without the need for transporting them?".

The use of scientific effects can be helpful at this moment. There is known what should be achieved. A purpose and principle are also known. Direction to the ideal state is clearer by finding several good inventive principles. To get closer to the information about possible answers to these questions the technical contradiction should be determined and resolved using inventive principles and the matrix to resolve technical contradictions. Several technical contradictions can be determined. Found principles are shown in the Table 2. The next step can be a determination of a physical contradiction. The main problem with all solutions is that there is a need for a crane for manipulation with one part in storage, but there is no money and space for purchasing a big crane for the storage building. Physical contradiction, in this case, can be formulated: there is a need for a crane to manipulate with parts in the storage, and on the other way, there should not be a crane because there is no money for that. Physical contradictions can be solved by separation in time, space, or principle.

By eliminating the crane from the system, a solution appears. Storage and assembly line should be placed together. In that case, there is no need for transportation. And parts can be taken one by one exactly by production demands. Unfortunately, there is no space and finance to manage the re-layout of the production plant. Another solution must be found. Some cheaper solution must be found. Separation in time - a crane is only needed when one part is handled. Separation in place - a crane, should be in storage, and after that, near to the assembly line. 
The whole process step by step is summarised in the Table 2 below.

Table 2 - Guided Problem Description Step by Step

\begin{tabular}{|c|c|}
\hline Problem & $\begin{array}{l}\text { - Parts are damaged during transport. } \\
\text { - There is a need for transporting parts back. }\end{array}$ \\
\hline Purpose & - To deliver parts to the line. \\
\hline Principle & - Transport on palettes. \\
\hline Ideal state & $\begin{array}{l}\text { - Exact number of parts safely delivered to line. } \\
\text { - There is no need for transport/transport back. }\end{array}$ \\
\hline Ideality questions & $\begin{array}{l}\text { - How can parts be transported in exact number? } \\
\text { - How to get parts by the line without transport? }\end{array}$ \\
\hline Technical contradiction & $\begin{array}{l}\text { 15. Dynamics, 2. Taking out, 17. Another dimension, 40. Composite } \\
\text { materials, 18. Mechanical vibration, 3. Local quality, 28. Mechanics } \\
\text { substitution, 32. Colour changes, 35. Parameter changes, 30. Flexible } \\
\text { shells and thin films, 34. Discarding and recovering, 2. Taking out }\end{array}$ \\
\hline Physical contradiction & $\begin{array}{l}\text { - There is a need for a crane, in order to manipulate with individual parts, } \\
\text { and there is a need to do not have the crane, in order to do not spend } \\
\text { much money. (Separate in time, space, principle) }\end{array}$ \\
\hline List of ideas & $\begin{array}{l}\text { - Only one part at once should be transported (or demanded number) } \\
\text { - Dynamic solution } \\
\text { - Use of another dimension } \\
\text { - Use of vibrations } \\
\text { - Use of gravity and other fields } \\
\text { - Use of thin protective layers } \\
\text { - Use of an object to transport which disappears } \\
\text { - It has to be cheap } \\
\text { - Re-layout (storage and line together) } \\
\text { - Crane is used when is manipulating with part (storage, line) }\end{array}$ \\
\hline
\end{tabular}

If these conclusions and previous conclusions from technical contradictions are put together, a solution to the problem can appear. It should transport only one part, dynamically, cheap, it uses a different dimension, the part is safe during the transport, it has something like crane during the handling in storage and near the assembly line.

Movable workshop cranes can be used. They are cheap, and they can lift exchangers easily in storage, parts are safe during the transport (they are surrounded by air), it uses another dimension - parts are hanging. An example of this crane is shown in the Figure 4 below.

It can be seen that a simple solution for the difficult problem can be found quite easily by the use of TRIZ principles. There were many tries to find a satisfying solution to this problem, and many employees tried to solve it using well-known tools of lean thinking or common sense. These tools were not enough. A more robust method was needed to find a suitable solution, which is the workshop crane. Probably there can be found another satisfying solution, maybe an even 
better one. With the presented method, it is possible to find a satisfying solution by industrial engineers in practice, not only by innovation and TRIZ experts.

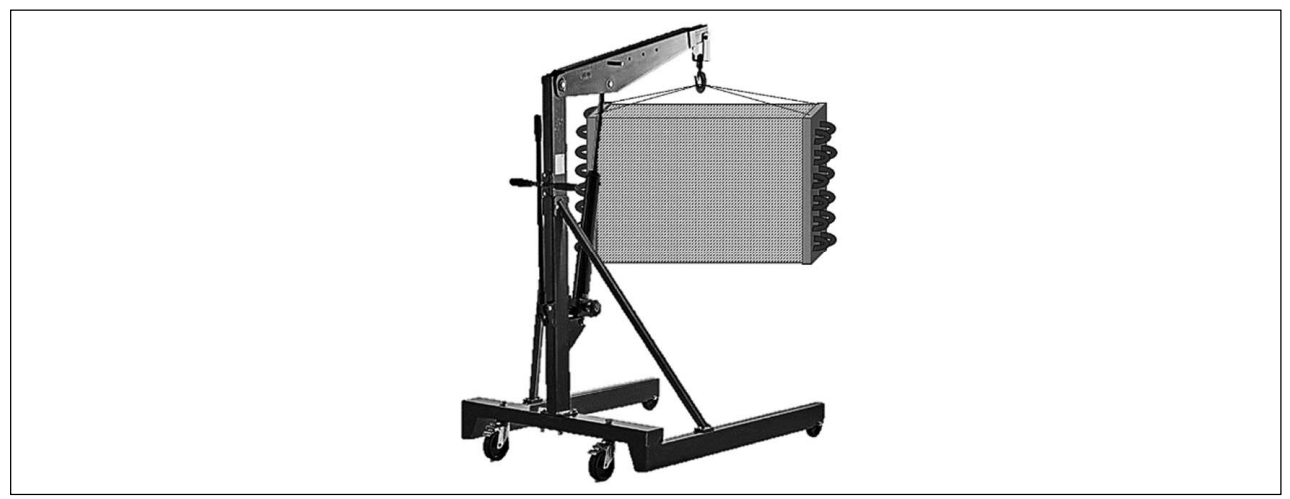

Figure 4 - Workshop Crane for the Safe Transport of Exchangers

\section{DISCUSSION}

When attempts to overcome a problem, from the case study presented above, are compared, a clear advantage of using TRIZ based approach appears. See a Table 3 below.

Table 3 - Comparison of Results from Classic Approach and Application of $3 I$

\begin{tabular}{|l|l|l|}
\hline Comparing parameter & Classic approach & $3 I$ \\
\hline Number of attempts & More than six attempts & Only one attempt \\
\hline Time for searching the solution & Years to search for a good solution & Days/weeks to apply the method \\
\hline Outcome & No satisfying solution found & Satisfying solution found \\
\hline
\end{tabular}

Previously many attempts during several years were tried, and no satisfying solution was found. The 3I method was used, and on the first attempt, a good solution to a problem was found. When a difficult problem occurs, the 3I method could help to overcome it faster. Deciding what a difficult problem is and what is not can be tricky. However, the method can also be used for easy problems or only after several false attempts. One can say the TRIZ itself can be used, and maybe even better results can be achieved. TRIZ is hard to learn and very hard to use for non-experienced users (Averboukh, 2003; Birdi, Leach and Magadley, 2012; Haines-Gadd, 2015; Ilevbare, Probert and Phaal, 2013; Nakagawa, 2011). The method of Innovation by Increasing Ideality (3I) leads the solver through the process of idea generation and use of TRIZ tools, so even with only basic knowledge of TRIZ's principles, quite good results could be achieved. This initial study was made only on one case study. That is why more applications of the 3I method are needed to verify its functionality. 
Many authors discuss problem-solving or process improvement by innovations. There are failures during the innovation attempts, which are caused mainly due to the lack of core competencies (Sawng, Shin and Kim, 2019). A model of innovative activity of industrial enterprises for managing innovative enterprise development is introduced by Gonchar, Cherep and Cherep (2019). Ouedraogo, Ouakouak and Salem (2020) discussed creative problem-solving and an approach for leading employees and managing innovation. A study presented by Zhu (2020) on how technological innovation is related to the age of employees points to focus on innovation education. The 3I method fits into these findings. It helps to resolve problems by the innovation of the process. The 3I method also helps to learn how to use TRIZ and systematic creativity way of thinking.

The following steps should lead to applying the 3I method to many different problems to get data about the real functionality of this proposed method. We believe that this method has the potential to be used not only for resolving problems but also for process innovation in general. For that purpose, some modifications to the method will probably follow.

\section{CONCLUSION}

As it was presented in the case study, TRIZ can help with the solution of difficult problems. When there is a guideline for describing a problem and how to proceed while resolving the problem, or innovation of the process step, even not TRIZ expertised solver can come up with a satisfying solution. If the time needed to resolve the problem is compared, the proposed 3I method is much faster than guessing and trying to resolve the problem in a traditional way. The use of the 3I method for description and overcoming difficult problems in production was shown in a case study from a real company. The solution to the problem with the transportation of heat exchangers between storage and production line was proposed to use workshop cranes. This application was here demonstrated only in one example. That is why more case studies and applications are needed to have strong proof, and this method works universally and well.

Results showed that this new method could help companies to overcome found problems in a shorter time and with higher efficiency. Because this new method is based on TRIZ techniques, better, more ideal solutions should be found. In the same way, the method is designed to be used by TRIZ beginners, there are no requirements for deep TRIZ knowledge, and still good and satisfying results could be found. The method should be applicable not only for problem-solving purposes but for process improvement in general. 


\section{ACKNOWLEDGEMENTS}

This work was supported by the Student Grant Competition of the Technical University of Liberec under the project No. SGS-2020-5027 - Research of new approaches to process improvement.

\section{REFERENCES}

Altshuller, G., 2000. The innovation algorithm: TRIZ, systematic innovation and technical creativity. 1. ed., 2. print. ed. Worcester, Mass: Technical Innovation Center.

Alves, A.C., Sousa, P. and Navas, H., 2020. Lean and TRIZ: From the Problems to Creative and Sustainable Solutions, Proceedings of the 6th European Lean Educator Conference, Lecture Notes in Networks and Systems. Springer International Publishing, Cham, pp.103-116. DOI: 10.1007/978-3-030-41429-0_11.

Anosike, A.I. and Lim, M.K., 2014. A Synergistic Approach to Process Innovation. International Journal of Knowledge, Innovation and Entrepreneurship, 2, pp.33-54.

Averboukh, E.A., 2003. I-TRIZ for Six Sigma Business Process Management. The TRIZ Journal, [online] 21 December 2003. Available at: <https://trizjournal.com/triz-six-sigma-business-process-management/> [Accessed 23 May 2021].

Azlan, A.D., Ariz, B. and Yusof, K.M., 2014. Perceptions on TRIZ by Current TRIZ Experts in the Industry: A review in Malaysia. In: IEEE, International Conference on Teaching and Learning in Computing and Engineering. Kuching, Malaysia, 11-13 April 2014. pp.325-331. CPS Conference Publishing Services.

Birdi, K., Leach, D. and Magadley, W., 2012. Evaluating the impact of TRIZ creativity training: an organisational field study: TRIZ training evaluation. $R \& D$ Manage, [e-journal] 42(4), pp.315-326. DOI: 10.1111/j.1467-9310.2012.00686.x.

Brad, S., 2010. Sigma-TRIZ: Algorithm for Systematic Integration of Innovation within Six Sigma Process Improvement Methodologies. In: A. Coskun, ed., Quality Management and Six Sigma. London: Intechopen Limited. pp.89-108.

Burch, G.F., Burch, J.J. and Batchelor, J.H., 2019. Group Creative Problem Solving: The Role of Creative Personality, Process and Creative Ability. Quality Innovation Prosperity, [e-journal] 23(3), pp.38-54. DOI: 10.12776/qip.v23i3.1286.

Caligiana, G., Liverani, A., Francia, D., Frizziero, L. and Donnici, G., 2017. Integrating QFD and TRIZ for innovative design. Journal of Advanced Mechanical Design Systems and Manufacturing, [e-journal] 11(2), 15p. DOI: 10.1299/jamdsm.2017jamdsm0015. 
Camarillo, A., Rios, J. and Althoff, K.-D., 2018. Knowledge-based multi-agent system for manufacturing problem solving process in production plants. Journal of Manufacturing Systems, [e-journal] 47(2018), pp.115-127. DOI: 10.1016/j.jmsy.2018.04.002.

Campos-Blázquez, J.R., Morcillo, P. and Rubio-Andrada, L., 2020. Employee Innovation Using Ideation Contests: Seven-Step Process to Align Strategic Challenges with the Innovation Process. Research-Technology Management, [e-journal] 63(5), pp.20-28. DOI: 10.1080/08956308.2020.1790237.

Choi, J., Lee, S. and Sawng, Y., 2019. The Dynamics of Industry Convergence in the Automotive Industry: A Technological Perspective Analysis Using Patent Data. Journal of Scientific and Industrial Research, Nov-2019, pp.760-765. Available at: <http://nopr.niscair.res.in/handle/123456789/51193> [Accessed 23 May 2021].

Domb, E., 1997. The Ideal Final Result: Tutorial. The Triz Journal, [online] 02 February 1997. Available at: 〈https://triz-journal.com/ideal-final-result-tutorial/> [Accessed 23 May 2021].

Domb, E., 2007. Ideality and Idealised Design. The Triz Journal, [online] 23 February 2007. Available at: <https://triz-journal.com/ideality-and-idealizeddesign/> [Accessed 23 May 2021].

Gonchar, O., Cherep, A. and Cherep, A., 2019. Substantiation of the model of innovative development of the enterprise. In: SMTESM-2019 (Strategies, Models and Technologies of Economic Systems Management), Proceedings of the 6th International Conference on Strategies, Models and Technologies of Economic Systems Management (SMTESM 2019). Khmelnytskyi, Ukraine, 4-6 Oct. 2019. Atlantis Press. DOI: 10.2991/smtesm-19.2019.69.

Gutiérrez-Ruiz, A.M., Valcarce-Ruiz, L., Becerra-Vicario, R. and Ruíz-Palomo, D., 2020. Identifying Industrial Productivity Factors with Artificial Neural Networks. Journal of Scientific and Industrial Research, [e-journal] Jun-2020, pp.534-536. Available at: <http://nopr.niscair.res.in/handle/123456789/54905> [Accessed 23 May 2021].

Haines-Gadd, L., 2015. Does TRIZ Change People? Evaluating the Impact of TRIZ Training within an Organisation: Implications for Theory and Practice. Procedia Engineering, [e-journal] 131, pp.259-269. DOI: 10.1016/j.proeng.2015.12.387.

Harlim, J. and Belski, I., 2015. On the Effectiveness of TRIZ Tools for Problem Finding. Procedia Engineering, TRIZ and Knowledge-Based Innovation in Science and Industry, [e-journal] 131, pp.892-898. DOI: 10.1016/j.proeng.2015.12.400.

Horvat, N., Skec, S., Perisic, M.M. and Bojcetic, N., 2020. Relating ProblemSolving Approach to Turn-Taking in Communication of Design Teams. Tehnički Vjesnik, [e-journal] 27(3), pp.703-710. DOI: 10.17559/TV-20180911161642. 
Horváthová, M., Lacko, R. and Hajduová, Z., 2019. Using Industry 4.0 Concept - Digital Twin - to Improve the Efficiency of Leather Cutting in Automotive Industry. Quality Innovation Prosperity, [e-journal] 23(2), pp.1-12. DOI: 10.12776/qip.v23i2.1211.

Ilevbare, I.M., Probert, D. and Phaal, R., 2013. A review of TRIZ, and its benefits and challenges in practice. Technovation, 33(2-3), pp.30-37. DOI: 10.1016/j.technovation.2012.11.003.

Jin, Y.T., San, Y.T. and Li, S.C., 2008. TRIZ: Systematic innovation towards factory operational efficiency. In: IEEE/CPMT (Institute of Electrical and Electronics Engineers / Components, Packaging, and Manufacturing Technology Society), 33rd IEEE/CPMT International Electronics Manufacturing Technology Conference. Penang, Malaysia, 4-6 Nov. 2008. Piscataway, NJ: IEEE. pp.1-4. DOI: 10.1109/IEMT.2008.5507846.

Lee, Z.Y., Lee, S.J. and Lin, G.T.R., 2019. Technology Function Analysis of Patent and Development Strategy for Robot Visual Servo. Journal of Scientific and Industrial Research, Jul-2019, pp.408-410. Available at: <http://nopr.niscair.res.in/handle/123456789/48792> [Accessed 23 May 2021].

Li, L., Li, D. and Yang, Y., 2011. The Design and Application of Synergetic Innovation System for Manufacturing Enterprise Based on TRIZ. In: IEEE (Institute of Electrical and Electronics Engineers), 2011 International Conference on Information Management, Innovation Management and Industrial Engineering. Shenzhen, China, 26-27 Nov. 2011. IEEE. pp.74-77. DOI: 10.1109/ICIII.2011.166.

Li, M., Ming, X., Zheng, M., He, L. and Xu, Z., 2017. An integrated TRIZ approach for technological process and product innovation. Proceedings of the Institution of Mechanical Engineers, Part B: Journal of Engineering Manufacture, [e-journal] 231(6), pp.1062-1077. DOI: $10.1177 / 0954405415583885$.

Lin, C.C., Lin, H.-H. and Huang, K.-C., 2016. TRIZ retrospect and prospect. In: IEEE (Institute of Electrical and Electronics Engineers), 3rd International Conference on Systems and Informatics (ICSAI). Shanghai, China, 19-21 Nov. 2016. IEEE. pp.1072-1076. DOI: 10.1109/ICSAI.2016.7811110.

Lin, C.-H., Lin, W.-T., Jou, Y.-T., Wu, W.-T. and Yan, Z.-H., 2016. A study of process optimisation for roasting Taiwanese coffees by applying Six Sigma. In: IEEE (Institute of Electrical and Electronics Engineers), 2016 International Conference on Fuzzy Theory and Its Applications (IFuzzy). Taichung, Taiwan, 9-11 Nov. 2016. IEEE. pp.1-8. DOI: 10.1109/iFUZZY.2016.8004963. 
Livotov, P., Chandra Sekaran, A.P., Law, R. and Mas'udah, Reay, D., 2018. Systematic Innovation in Process Engineering: Linking TRIZ and Process Intensification. In: S. Koziołek, L. Chechurin, eds. 2018. Advances in Systematic Creativity: Creating and Managing Innovations. Cham: Palgrave Macmillan. pp.27-44. DOI: 10.1007/978-3-319-78075-7_3.

Maia, L.C., Alves, A.C. and Leão, C.P., 2015. How Could the TRIZ Tool Help Continuous Improvement Efforts of the Companies?. Procedia Engineering, [e-journal] 131, pp.343-351. DOI: 10.1016/j.proeng.2015.12.412.

Meister, M., Beßle, J., Cviko, A., Böing, T. and Metternich, J., 2019. Manufacturing Analytics for problem-solving processes in production. Procedia CIRP, [e-journal] 81, pp.1-6. DOI: 10.1016/j.procir.2019.03.001.

Menon, N., Mishra, A. and Ye, S., 2020. Beyond Related Experience: Upstream vs. Downstream Experience in Innovation Contest Platforms with Interdependent Problem Domains. M\&SOM, [e-journal] 22(5), pp.1045-1065. DOI: 10.1287/msom.2019.0794.

Mohammed, K.M.C., Kumar, S.S. and Prasad, G., 2020. Optimised Fuzzy Cmeans Clustering Methods for Defect Detection on Leather Surface. Journal of Scientific and Industrial Research, Sep-2020, pp.833-836. Available at: <http://nopr.niscair.res.in/handle/123456789/55419> [Accessed 23 May 2021].

Morgado, T.L.M., Sandiães, J. and Navas, H.V.G., 2019. TRIZ and Lean Philosophies Applied Together in Management Activities. Quality Innovation Prosperity, [e-journal] 23(3), pp.90-102. DOI: 10.12776/qip.v23i3.1289.

Nakagawa, T., 2011. Education and training of creative problem solving thinking with TRIZ/USIT. Procedia Engineering 9, pp.582-595. DOI: 10.1016/j.proeng.2011.03.144.

Navas, H.V.G., 2017. Problem Solving and Increase of Ideality of Complex Systems. In: F.-J. Kahlen, S. Flumerfelt and A. Alves, eds. 2017. Transdisciplinary Perspectives on Complex Systems: New Findings and Approaches. Cham: Springer International Publishing. pp.305-327. DOI: 10.1007/978-3-319-38756-7_11.

Ouedraogo, N., Ouakouak, M.L. and Salem, T., 2020. Effectts of Employee Creative Problem-Solving on Innovation outcomes and Non-Financial Performance: The Moderating Role of Culture and Communication. International Journal of Innovation Management, [e-journal] 24(7), 2050069. DOI: 10.1142/S1363919620500693.

Russo, D. and Spreafico, C., 2020. TRIZ-Based Guidelines for Eco-Improvement. Sustainability, [e-journal] 12(8), 24p. DOI: $10.3390 /$ su12083412. 
Sawng, Y., Shin, J. and Kim, M., 2019. A Reconsideration of Innovation Failure: Evidence from the Korea Innovation Survey. Journal of Scientific and Industrial Research, Dec-2019, pp.822-826. Available at: <http://nopr.niscair.res.in/handle/123456789/52222> [Accessed 23 May 2021].

Shahzad, A., Gulzar, W.A. and Shahzad, A., 2020. A Single Machine Scheduling Problem with Individual Job Tardiness based Objectives. Journal of Scientific and Industrial Research, May-2020, pp.377-382. Available at: <http://nopr.niscair.res.in/handle/123456789/54707> [Accessed 23 May 2021].

Slocum, M., Lundberg, C., Walter, K., 2003. Reangularity, Semangularity, and Ideality. The Triz Journal. URL: <https://triz-journal.com/reangularitysemangularity-ideality/> [Accessed 23 May 2021].

Soderlin, P., 2003. Thoughts on Value and Ideality, Is the Concept of Ideality "Scientific"? The Triz Journal, [online] 20 May 2003. Available at: <https://trizjournal.com/thoughts-value-ideality-concept-ideality-scientific/> [Accessed 23 May 2021].

Sojka, V. and Lepšík, P., 2020a. Use of TRIZ, and TRIZ with Other Tools for Process Improvement: A Literature Review. Emerging Science Journal, [e-journal] 4(5), pp.319-335. DOI: 10.28991/esj-2020-01234.

Sojka, V. and Lepšík, P., 2020b. TRIZ Tools for Manufacturing Processes Improvement. In: P. Ondra, 2020, 16th International Bata Conference for Ph.D. Students and Young Researchers. Zlín, Czech Republic, 2-3 Sept. 2020. Zlín: Tomas Bata University in Zlín. pp.484-491. DOI: 10.7441/dokbat.2020.41.

Song, W. and Sakao, T., 2017. A customisation-oriented framework for design of sustainable product/service system. Journal of Cleaner Production, [e-journal] 140(3), pp.1672-1685. DOI: 10.1016/j.jclepro.2016.09.111.

Swee, N.S.L., Toh, G.G., Yip, M.W., Keong, C.S. and Tai, S.C., 2017. Applying Triz for Production Quality Improvement. In: H.L. Yuan, R.K. Agarwal, P. Tandon and E.X. Wang, eds. MATEC Web Conf., 2016 the 3rd International Conference on Mechatronics and Mechanical Engineering (ICMME 2016). Shanghai, China, October 21-23, 2016. MATEC-Conferences. DOI: 10.1051/matecconf/20179510009.

Wu, Y.-C., Lin, G.T.R. and Yu, W.-H., 2019. How to Enhance Customer Involvement in Service Innovation within Service Industry. Journal of Scientific and Industrial Research, Jun-2019, pp.342-344. Available at: <http://nopr.niscair.res.in/handle/123456789/47563> [Accessed 23 May 2021].

Zhu, Y., 2020. The Influence of Aging on Technological Innovation: Empirical Evidence from China. Journal of Scientific and Industrial Research, Dec-2020, 1110-1115. Available at: <http://nopr.niscair.res.in/handle/123456789/55725> [Accessed 23 May 2021]. 


\section{ABOUT AUTHORS}

Vladimir Sojka ${ }^{0000-0001-7295-8160}$ (V.S.) - Department of Machine Design and Mechanisms, Faculty of Mechanical Engineering, Technical University of Liberec, Czech Republic, Ph.D. Student, e-mail: vladimir.sojka@tul.cz.

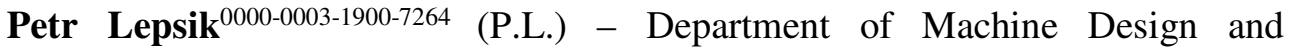
Mechanisms, Faculty of Mechanical Engineering, Technical University of Liberec, Czech Republic, Vice-Dean for Doctoral Studies and Development, Assoc. Prof., e-mail: petr.lepsik@tul.cz.

\section{AUTHOR CONTRIBUTIONS}

Conceptualization, V.S.; Methodology, V.S. and P.L.; Literature review, V.S.; Original draft preparation, V.S.; Review and editing, P.L.; Supervision, P.L.

\section{CONFLICTS OF INTEREST}

The authors declare no conflict of interest. The funders had no role in the design of the study; in the collection, analyses, or interpretation of data; in the writing of the manuscript, or in the decision to publish the results. 